\title{
UM NOVO OLHAR SOBRE A ELABORAÇÃO DE MATERIAIS DIDÁTICOS PARA EDUCAÇÃO EM SAÚDE
}

\section{A NEW LOOK ON THE PREPARATION OF TEACHING MATERIALS FOR HEALTH EDUCATION}

\author{
Samuel Quinaud Rossi ${ }^{1}$ \\ Vinícius Silva Belo ${ }^{2}$ \\ Bruno Warlley Leandro Nascimento ${ }^{3}$ \\ Jacqueline da Silva ${ }^{4}$ \\ Priscila Correia Fernandes ${ }^{5}$ \\ Eduardo Sérgio da Silva ${ }^{6}$
}

Resumo O presente artigo tem como objetivo lançar um olhar crítico sobre o processo de elaboração de um conjunto de materiais didáticos em Educação em Saúde, produzido a partir do ano de 2007 na Universidade Federal de São João del-Rei, para uso em um programa que visava o combate a parasitoses intestinais. Os materiais foram analisados de forma a se avaliar as potencialidades e as deficiências encontradas. Como resultado, obteve-se a necessária reelaboração deles, com o objetivo de que sejam utilizados como meios educativos que respeitem identidades e contribuam para a construção de saberes em relação à saúde. Espera-se que as propostas de reelaboração e correção, juntamente com as características positivas analisadas, possam colaborar com a produção de novos materiais e contribuir para a melhoria da oferta de produtos que medeiem o processo de construção de conhecimentos na área da saúde.

Palavras-chave educação em saúde; materiais didáticos; ilustrações.
Abstract This article aims to cast a critical eye on the preparation process used for a set of teaching materials in health education, which was produced from 2007 at the Federal University of São João del Rei for use in a program aimed at combating intestinal parasites. The materials were analyzed in order to address the strengths and weaknesses that were found. As a result, such materials were reworked for use as educational media that respect identities and contribute to building knowledge on health. It is expected that the proposals that were made for material redesign and correction, along with the positive characteristics that were analyzed, may contribute to the production of new materials and contribute to improving the supply of products that mediate the process of building knowledge in health.

Keywords health education; educational materials; illustrations. 


\section{O momento preparatório: as bases para a produção}

No ano de 2007, um grupo de professores e alunos da Universidade Federal de São João del-Rei deu início ao programa de pesquisa e extensão intitulado "Educação, saúde e análise de prevalência de enteroparasitoses intestinais em escolares da rede municipal de São João del-Rei, Minas Gerais". Tal programa foi proposto e coordenado pela equipe da universidade que contou com a parceria das secretarias municipais de saúde, de educação e de meio ambiente do município. O programa se destinava a crianças de sete a 11 anos, matriculadas no ensino fundamental de escolas públicas de São João del-Rei, junto às quais se desenvolveu as seguintes atividades: coleta e exame de fezes de toda a população escolar; exames malacológicos dos cursos d'agua; análise epidemiológica dos resultados parasitológicos e malacológicos; distribuição de tratamento conforme demanda; e Educação em Saúde para prevenção de parasitoses intestinais nas escolas participantes. Além disso, pais e professores, que foram co-participantes do projeto, atuaram como mediadores das coletas e participaram de encontros de divulgação sobre ações de promoção da saúde. As atividades educativas foram coordenadas por alunos e professores da universidade. As ações de Educação em Saúde ainda contemplaram a produção de uma série de materiais didáticos ilustrados para serem utilizados dentro do referido programa, sendo estes os objetos de análise deste trabalho.

A elaboração dos materiais didáticos foi orientada pela preocupação com a forma com que o conjunto de imagens produzido seria utilizado, uma vez que se tinha como pressuposto o grande poder de atração que as ilustrações são capazes de gerar, com vistas ao envolvimento dos alunos nas discussões sobre parasitoses. O material deveria ser adequado para a sua utilização durante as visitas às escolas, durante a preparação para a coleta do material biológico para exames, e deveria permanecer nestas instituições de ensino como fonte de informações adicionais após o término do projeto.

Dessa forma, foram utilizados os fatores que orientam o processo de elaboração de ilustrações citados por Morato et al. (1998). Para estes autores, anteriormente ao trabalho produtivo, pensar em três questões se faz tarefa essencial: o que, para quem e como. O conteúdo da informação que se deseja transmitir, o público ao qual esta informação se destina, o melhor tratamento da informação e o meio de comunicação mais adequado são fatores que devem ser constantemente lembrados. Tais questões nos fazem perceber que cada área do conhecimento e cada público alvo requerem diferentes exigências, que devem ser levadas em conta durante a produção das ilustrações a serem utilizadas. De acordo com Oliveira e Conduru (2004), o resultado final deste processo não pode se dissociar dos propósitos do meio no qual e para o qual foram produzidas. 
Em concordância com Bruzzo (2004), não tínhamos as imagens como um simples aspecto de deleite ou distração, mas como fontes de influência no processo de aprendizado, modificando a maneira de compreensão de determinada área de conhecimento, aqui, a Educação em Saúde, e atuando na prática e na reflexão educativas. Buscava-se ainda que as imagens pudessem estimular a ética e a sensibilidade dos alunos que com elas tivessem contato.

Assim como ressaltam Queiroz e Barbosa-Lima (2007), tínhamos como objetivo que os materiais elaborados levassem em conta a importância de se fornecer aos alunos o contato com diversos modelos alternativos na interpretação da natureza, o que ajudaria não só na compreensão mais clara do que seria estudado, como ainda colaboraria para um melhor entendimento das formas de construção do conhecimento.

Adotamos uma visão de Educação em Saúde como ferramenta capaz de atuar no desenvolvimento intelectual dos estudantes e na promoção de conhecimentos que favoreçam o exercício da cidadania, formando indivíduos conscientes de seus direitos e deveres em sociedade, dados os questionamentos políticos, sociais e ambientais que devem permear este campo educativo. Goldberg, Yunes e Freitas (2005) defendem uma educação como formadora de cidadãos "capazes de participar de tomadas de decisão na esfera das políticas públicas e de reconhecer os problemas socioambientais atuais para os quais se buscam soluções individuais ou coletivas" (Goldberg, Yunes e Freitas, 2005, p. 105). Compartilhando pontos de vista semelhantes, estão Succi, Wickbold e Succi (2005) que veem a Educação em Saúde como importante meio de possibilitar às crianças a divulgação no ambiente familiar do que se aprendeu em sala de aula, executando práticas de proteção à saúde, transformando-as em promotoras da saúde. Assim, as crianças em idade escolar, público alvo de nosso projeto, foram consideradas como indivíduos pertencentes à sua comunidade, capazes de atuar em suas esferas sociais (família, escola etc.), e que deveriam ser fortalecidas pelo acesso a informações relacionadas ao seu próprio corpo, à sua comunidade e ao meio ambiente. 
Com base nestes elementos, foram produzidos, no total, oito cartazes (Figura 1) relacionados a oito patologias diferentes (ancilostomose, amebíase, ascaridíase, doença de Chagas, esquistossomose, giardíase, pediculose e teníase), compondo uma série de materiais que traziam como marca um conjunto de características capazes de gerar reflexões, como as que serão discutidas a seguir.

Figura 1

Conjunto de cartazes produzido. Cada cartaz possui tamanho aproximado de uma folha A3 ( $297 \mathrm{~mm}$ x $420 \mathrm{~mm}$ )

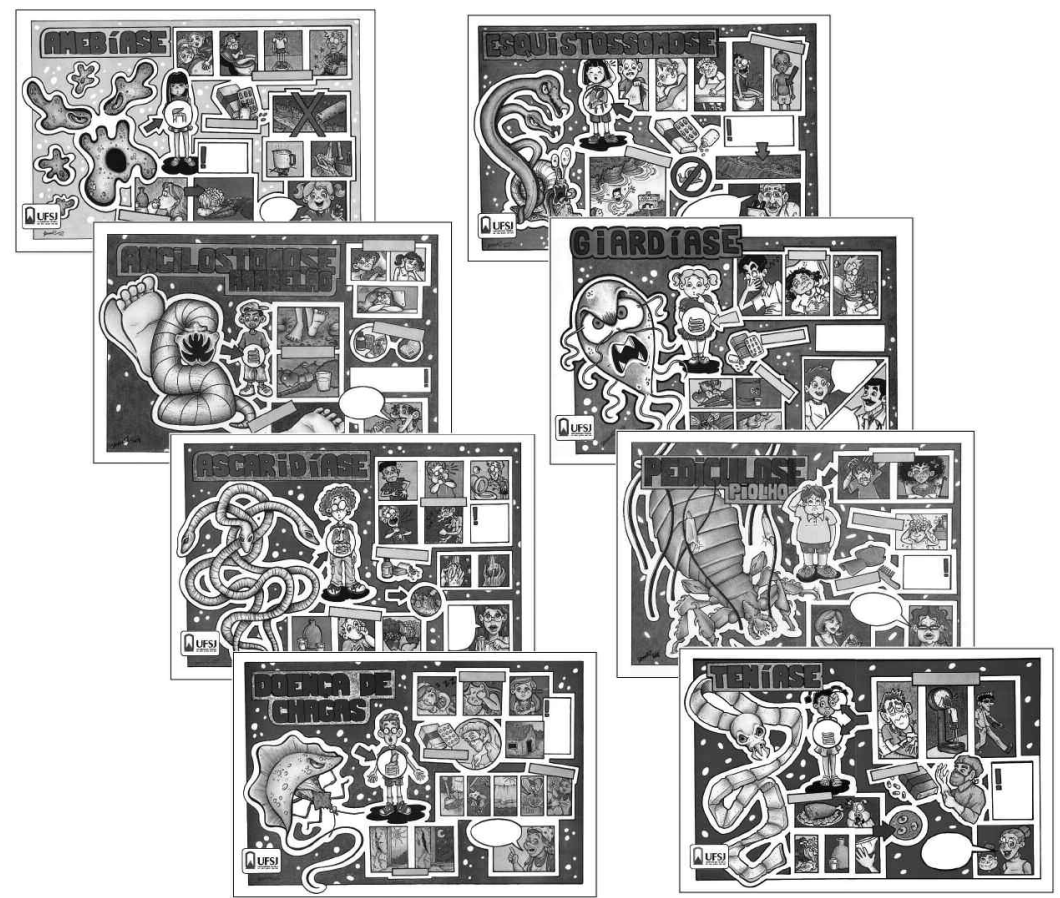

\section{E nascem os materiais: os pontos positivos em questão}

No início da confecção destes materiais tinha-se como foco somente enteroparasitoses intestinais, porém, com o avançar das produções, também foram produzidos materiais destinados a parasitoses não intestinais (esquistossomose, doença de Chagas e pediculose). Esta mudança ocorreu em função da demanda observada nas comunidades trabalhadas (ocorrência de pediculose em algumas) e pela solicitação dos professores devido à presença do conteúdo nos currículos formais de ciências para o ensino fundamental (caso da esquistossomose e doença de Chagas). 
Todos os cartazes produzidos possuem traços em comum (Figura 2) que, ao todo, dão forma a uma série de pontos de reflexão dentro do trabalho educativo. Considerando a análise curricular discutida por Silva (2010), os materiais didáticos aqui analisados configuram-se como elementos constituintes do currículo escolar, uma vez que se fazem presentes dentro da escola, atuando como temas geradores de discussões e aprendizados. A seguir, cada um destes traços será posto em reflexão.

Figura 2

Esquema em que são mostrados os traços em comum entre os cartazes. Os números na figura acima se referem a: 1) Personagens; 2) Cores; 3) Espaços em branco; 4) Situações diversas; 5) Modelo de história em quadrinhos; 6) Etnias.

1)

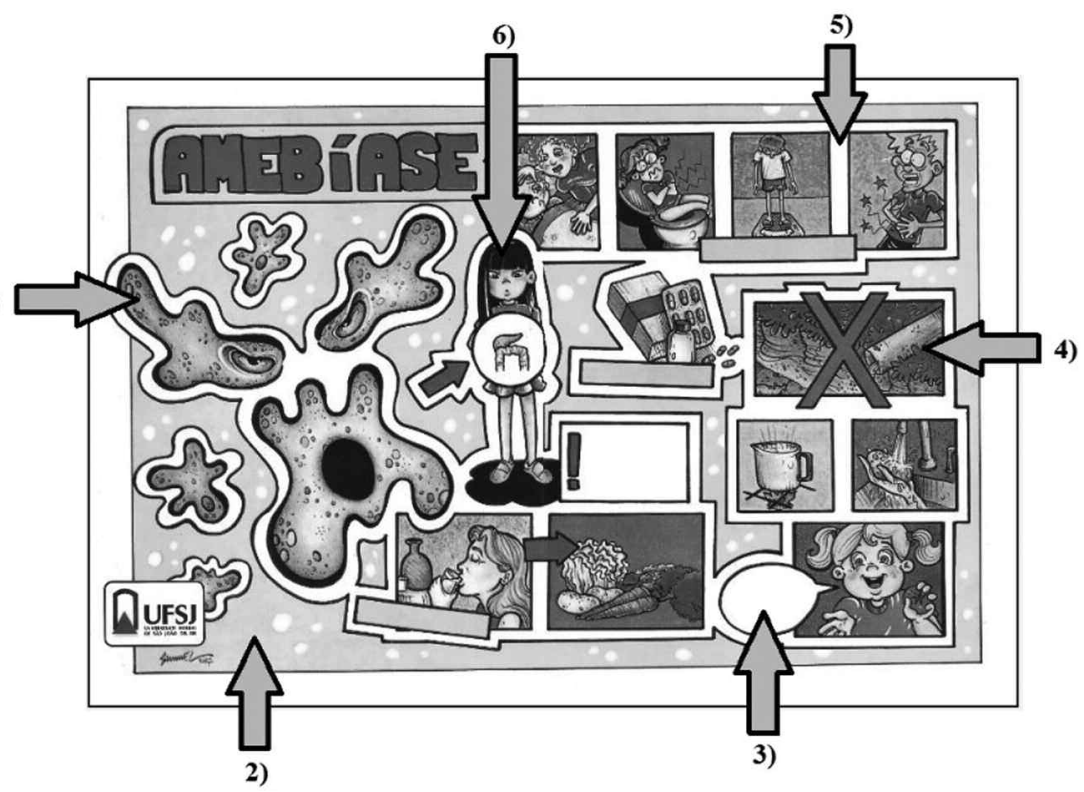

1) Personagens: grande espaço dos cartazes foi destinado à representação dos organismos parasitas, ocupando cerca de $1 / 3$ destes. Rossi (2008), ao analisar o modelo adotado de se ilustrar os parasitos nestes materiais, acredita que

(...) a busca de novas formas de representação desses seres, que não fujam completamente da realidade, mas que construam imagens alegóricas dos organismos, é de grande importância durante o aprendizado inicial (...). Tendo o aluno uma concepção inicial formada a respeito desses organismos e doenças, o seu aprendizado mais aprofundado certamente será facilitado, uma vez que o que ele terá em mente não será uma imagem distorcida e confusa, e sim algo dentro de sua realidade (Rossi, 2008, p. 13). 
Tanto os parasitos quanto os personagens foram ilustrados em estilo cartoon, cuja finalidade foi atrair os alunos e aumentar as possibilidades de familiaridade com os organismos, fazendo com que o aprendizado se tornasse mais agradável. Apesar do formato adotado, buscou-se manter os traços naturais destes organismos, tentando amenizar as possíveis alterações da produção.

2) Cores: certamente, um dos traços mais marcantes deste conjunto de materiais diz respeito à coloração empregada. Cada cartaz foi pensado para exibir cores chamativas, seja de fundo (amebíase/amarelo, ancilostomose/rosa, ascaridíase/laranja, doença de Chagas/violeta, esquistossomose/verde, giardíase/azul, pediculose/marrom, teníase/vermelho), nas cenas exibidas, ou nas personagens. Assim como afirmam Oliveira e Conduru (2004), se o material é destinado a leitores menos especializados, o apelo visual é mais importante que o compromisso com a precisão científica. Para Rossi (2006), “as cores vivas atraem a atenção dos alunos, possibilitando um maior interesse" (Rossi, 2006, p. 6). Buscamos conciliar ambos os aspectos no material desenvolvido, ou seja, elaborar um produto esteticamente interessante e atrativo, sem deixar de lado o compromisso com a precisão das informações nele contidas, algo que foi facilitado pela utilização de imagens, cores e alegorias.

3) Espaços em branco: em todos os cartazes há espaços vazios, caixas de diálogo e lacunas. Esses espaços são aberturas ao leitor do cartaz, são provocações à participação e convites para a cooperação na construção dos conhecimentos propostos. As lacunas provocam o leitor a participar e a investigar os elementos que completarão a imagem. Além disso, os espaços vazios aumentam as possibilidades de valorização do conhecimento prévio dos alunos, fazendo do ensino um processo misto de direcionamento e liberdade, como denominado por Cunha (2001), possibilitando a construção de conhecimentos efetivos.

Freire (2009) descreve que ao educador e à escola cabe o dever não somente de respeitar os saberes com que os educandos, sobretudo das classes populares, chegam à escola, mas também, de discutir a razão de ser destes saberes em relação ao ensino dos conteúdos. Neste contexto, tal característica do material pode fazer com que as possibilidades de investigação dos saberes dos alunos sejam potencializadas. No momento em que se tem em mãos um material que estimula a discussão, que permite o reconhecimento da provisoriedade do saber e a valorização das realidades e necessidades específicas das comunidades, ao mesmo tempo em que ajuda a tornar a escola um espaço democrático, que valoriza os conhecimentos prévios dos estudantes, aumentam-se as chances de que se capacite os sujeitos a tomar decisões, modificando comportamentos e promovendo mudanças sociais, objetivos fundamentais da Educação em Saúde (Candeias, 1997; Schall e Struchiner, 1999). 
4) Situações diversas: está presente, também, nos cartazes uma diversidade de situações que servem para ilustrar variadas formas de contaminação, medidas profiláticas, sintomas das doenças e locais onde os parasitos se instalam no corpo humano. Buscou-se, apesar da seriedade do tema proposto, que estas situações fossem representadas de forma humorada, que pudessem ser familiares aos leitores e, também, ensinar. Não fugir da realidade social das crianças foi um dos objetivos durante a produção dos materiais. Buscou-se ilustrar diferentes realidades das comunidades onde o material seria utilizado, como é o caso das cenas de esgoto correndo a céu aberto nos cartazes da esquistossomose, amebíase e giardíase, buscando-se produzir um produto que não tivesse um caráter meramente informativo, mas que estimulasse a reflexão sobre a realidade dos locais onde se vive e as relações entre esta e os riscos à saúde e ao bem-estar. Essa contextualização só foi possível pelo contato prévio da equipe produtora do material com as comunidades escolares onde esse material seria utilizado. Esse contato foi estabelecido em projetos anteriores de pesquisa etnográfica (Facion e Fernandes, 2008a; Facion e Fernandes, 2008b) e de extensão universitária.

5) Modelo de histórias em quadrinhos: o molde no qual foram elaborados os materiais também serve como interessante ponto de análise. Nota-se o formato adotado, semelhante ao de histórias em quadrinhos, escolhido devido à influência destas no meio infantil e ao provável papel atrativo que poderia proporcionar. A escolha deste formato torna-se pertinente a partir do momento em que estudos como os de Fogaça (2002) afirmam que, entre todas as linguagens que fazem parte do mundo contemporâneo, a história em quadrinhos realiza a integração entre a linguagem escrita e visual, atuando na construção de conhecimentos, na atribuição de sentidos e na formação de competências artísticas, literárias e linguísticas pelos alunos.

Caruso, Carvalho e Silveira (2002) enfatizam a utilização de tirinhas e de histórias em quadrinhos para a disseminação do conhecimento. Segundo estes autores, as tirinhas têm grande poder de concisão, ressaltando a linguagem da imagem, objetivando a fuga de qualquer tipo de memorização e despertando a curiosidade do aluno, permitindo que ele reflita e aprenda por meio de suas próprias deduções e conclusões, mesmo que, para isso, ele necessite da ajuda de seu professor. Uma vez que foram produzidas tirinhas em que as histórias e falas seriam contadas pelos próprios alunos, o material foi pensado para o uso em programas de Educação em Saúde com a participação de mediadores. A mediação inicial foi feita pela própria equipe do projeto, nos encontros iniciais com os alunos e professores. Os cartazes foram então deixados nas escolas para posteriores utilizações, de acordo com as atividades propostas pelos professores. 
6) Etnias: procurou-se, ainda, fazer dos cartazes meios multiculturais, onde estariam representadas as mais variadas etnias, indo ao encontro das perspectivas humanistas apontadas por Silva (2010), na defesa da igualitária representação dos diferentes grupos culturais por sua comum humanidade. Desta forma, pretendíamos que as diferentes culturas fossem representadas epistemológica e antropologicamente de formas equivalentes.

A meta seria, assim como aponta Rossi (2008), que, "quando esses desenhos fossem mostrados nas escolas, houvesse identificação pessoal dos alunos, aumentando sua capacidade de comunicação" (Rossi, 2008, p. 14), uma vez que, de acordo com Fogaça (2002), quando são representadas crianças passando por situações corriqueiras da vida real, as possibilidades de atração para o leitor são potencializadas.

Com o passar do tempo e com a utilização do material no programa educativo, pudemos reanalisar estes materiais, lançando um novo olhar sobre eles no qual novos aspectos se fizeram fundamentais como meios de reflexão. A análise da utilização posterior desses materiais pelos próprios professores das escolas, bem como sua efetiva utilização no cotidiano escolar são pontos ainda a ser esclarecidos e que merecerão atenção em pesquisas futuras.

Torna-se óbvio que, como 'materiais didáticos', atuantes na construção de conhecimentos e na dinâmica escolar, estes cartazes carregam consigo grandes responsabilidades, as quais exigem generosa carga de criticidade e cuidado durante o processo de produção, sendo sua análise posterior, necessária e fundamentalmente, mais rigorosa.

\section{A fuga do propósito: investigando os pontos negativos}

Alguns anos após a criação do material, diante do aprofundamento no estudo sobre produção de materiais didáticos, foi possível identificar nesses cartazes inúmeras falhas de ordem ideológica, metodológica e conceitual. Essa crítica é salutar, pois propõe uma reflexão sobre o trabalho de produção de materiais didáticos e identifica seus processos de elaboração, em um grupo que vem desenvolvendo materiais para apoio a projetos de ensino-pesquisaextensão na universidade.

A primeira característica que apontamos é de ordem conceitual. A forma de representação dos organismos foi um dos pontos mais criticados durante a utilização dos cartazes nas escolas e principalmente na divulgação destes materiais em eventos relacionados à área de Educação em Saúde. Certamente, não foi o estilo cartoon e a consequente ludicidade criada por eles que foi alvo de críticas, mas, sim, o aspecto negativista que carregam. 
Se os cartazes foram produzidos em formato de história em quadrinhos, então os parasitos representaram o papel dos vilões (Figura 3). Esse aspecto 'mau' atribuído a estes personagens pode gerar um duplo resultado: a real necessidade de se evitar a contaminação das doenças por eles causadas; mas, também, gerar no público alvo o medo de se imaginar parasitado por esses vilões de aspecto aterrorizador. Sob outro ponto de vista, se imaginarmos estes organismos como seres vivos que são, deveríamos, então, reconhecêlos apenas em sua importância como cumpridores de seu papel biológico. Seria, então, educativo atribuir a eles este caráter negativista?

Figura 3

Em destaque, os parasitos como 'vilões'

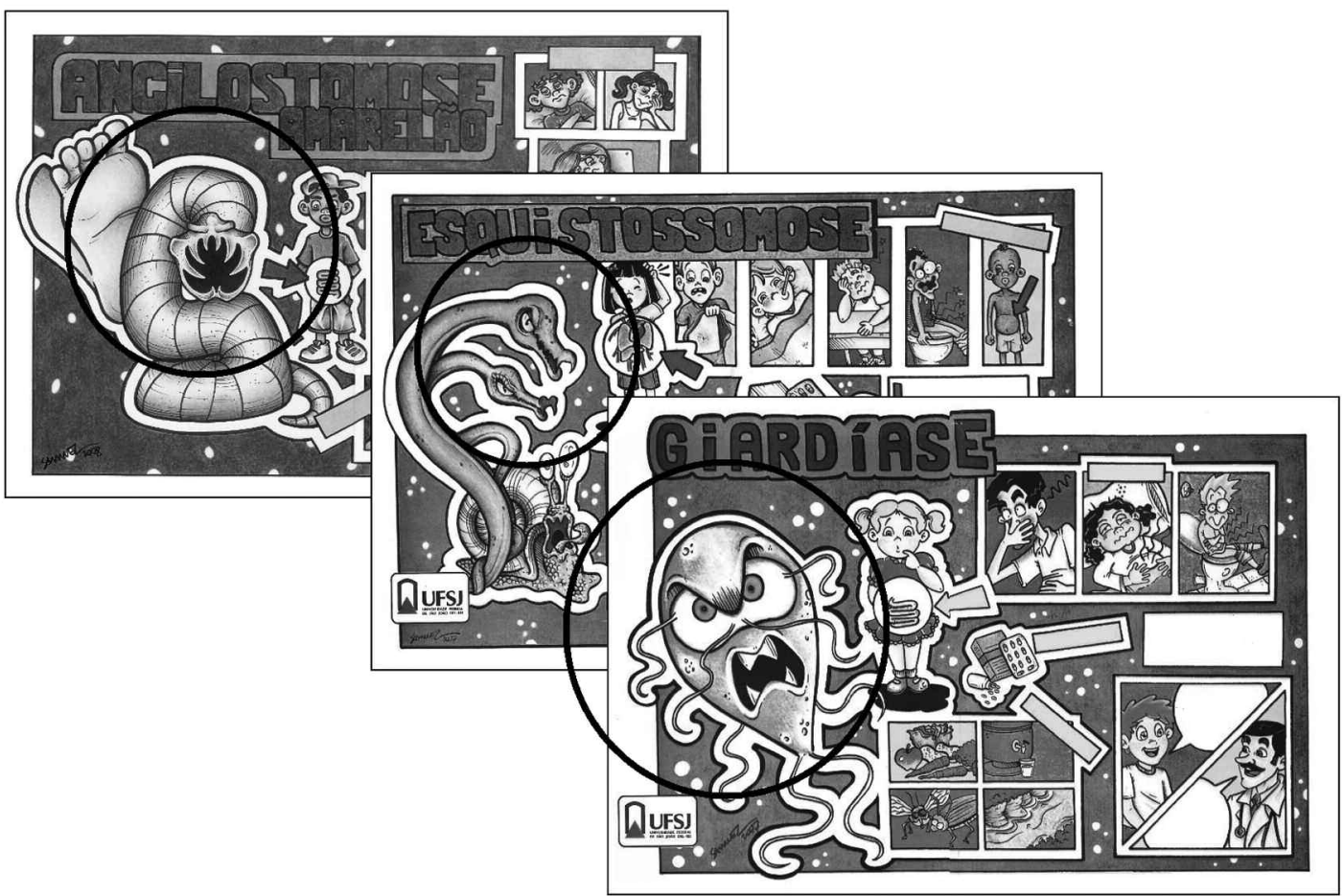


Além deste fator, pode-se notar que as escalas adotadas de representação destes organismos podem gerar confusão nos estudantes. Não se pode negar que um leitor principiante, ao ter contato com as imagens do cartaz da doença de Chagas (Figura 4), por exemplo, certamente, poderia imaginar que o protozoário (Trypanosoma cruzi) causador da doença seja maior que, ou tão grande quanto, o barbeiro, vetor. Mohr (2000) discute que este é o tipo de erro mais comum existente nos livros didáticos de ciências, e que é possível desenhar os organismos em escala junto a objetos mais conhecidos, representando ainda os organismos microscópicos sob uma lente de aumento.

Figura 4

Confusões com a escala: protozoário e barbeiro no cartaz 'doença de chagas'

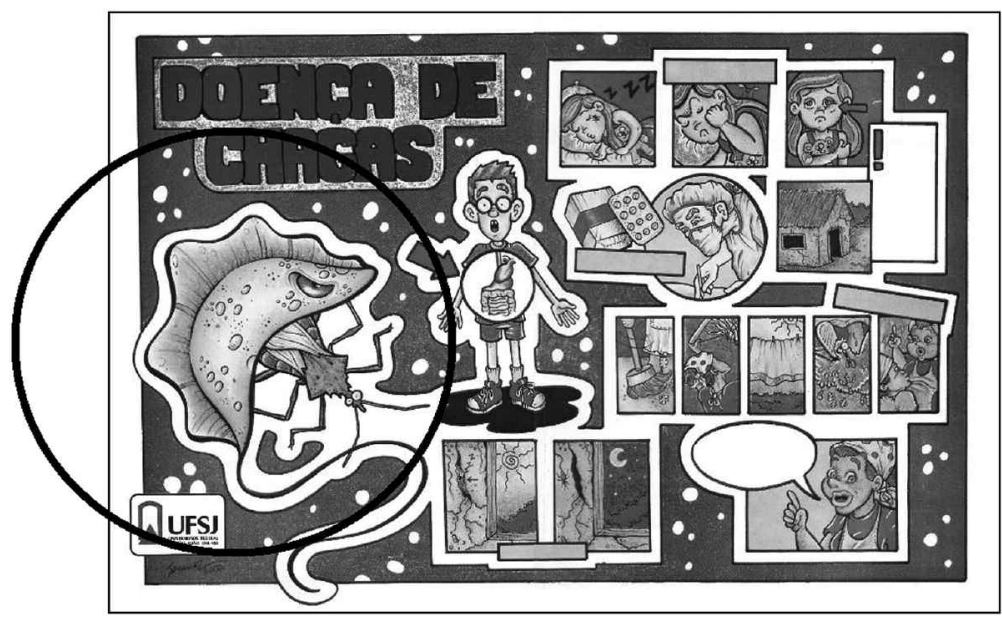

Outro ponto problemático e que deve ser analisado se refere às figuras humanas representadas. Desde que se deu início à produção destes materiais, a meta seria que, de forma alguma, seriam reforçados estereótipos ou induzidos preconceitos. Autores como Succi, Wickbold e Succi (2005) e Santos et al. (2007) contribuíram nesta meta, ao ressaltar o quão negativo é, para o processo de aprendizagem, quando as ilustrações reforçam situações indesejáveis, como aquelas que tínhamos como tarefa evitar. 
Se fizermos uma análise de como as relações de gênero são tratadas nestes materiais, podemos encontrar características que vão ao encontro das críticas feitas por Silva (2010). Certos elementos presentes nos cartazes claramente contribuem para reforçar estereótipos ligados a gênero. Podemos observar, por exemplo, que os médicos e cientistas presentes nos materiais foram sempre representados pela figura masculina, enquanto as figuras femininas representavam 'mulheres comuns' (Figura 5). Para Silva (2010), características como estas contribuem para que os próprios professores, inconscientemente, esperem coisas diferentes de meninos e meninas, podendo determinar a carreira educacional desses jovens, reproduzindo, assim, as desigualdades de gênero.

Figura 5

Exemplos das relações de gênero tratadas nos cartazes
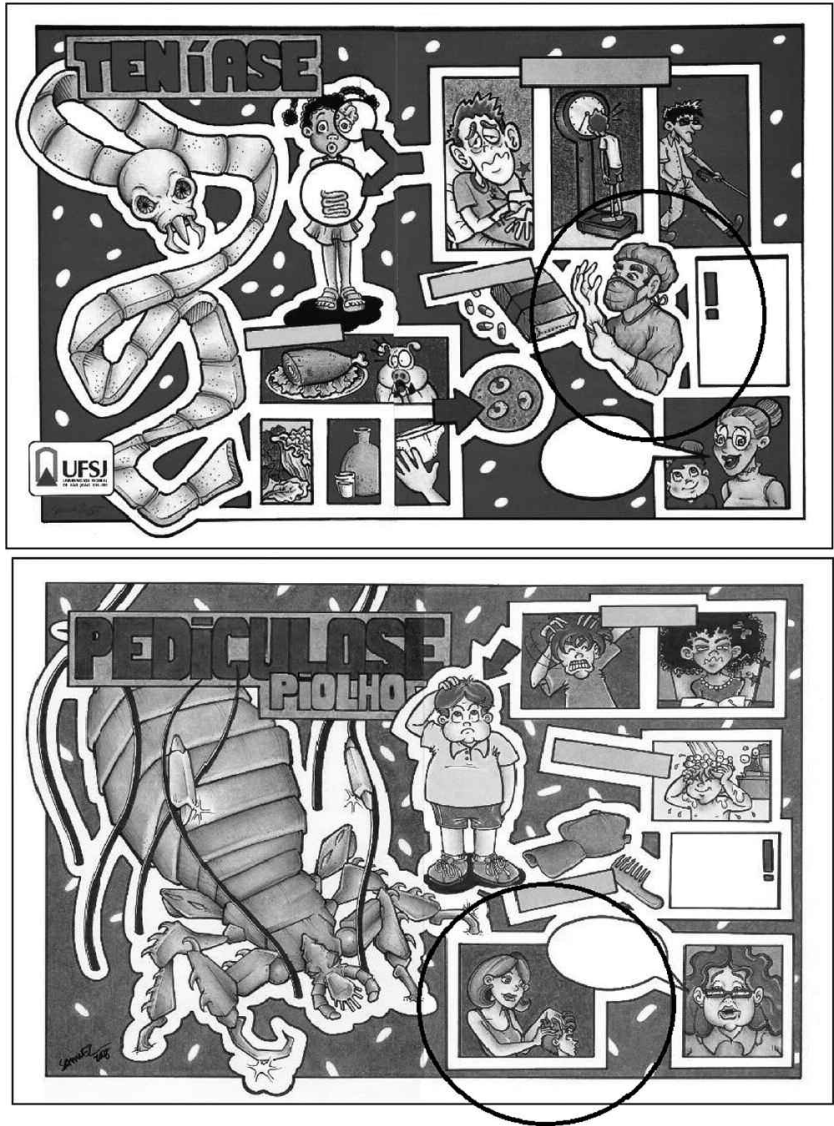
Ponto tão delicado quanto este é a forma como questões étnicas foram tratadas nestes materiais didáticos. Ao contrário da perspectiva crítica defendida por Silva (2010), dois cartazes específicos (esquistossomose e doença de Chagas), longe de contribuírem para a desconstrução dos estereótipos criados ao longo da história da humanidade, no que se refere a questões étnicas e raciais, só os reforçam. A ilustração criada de uma mulher negra, representada por suas vestimentas como faxineira, de lenço na cabeça e avental, ou da ilustração do menino negro com barriga d'água (Figura 6) servem como base de questionamentos sobre o papel destes cartazes como confirmadores dos privilégios das identidades dominantes e tratando as identidades dominadas como exóticas ou folclóricas, podendo atuar na conservação das marcas da herança colonial, assim como avalia Silva (2010, p. 101).

Figura 6

Ilustrações presentes nos cartazes em que florescem questões raciais
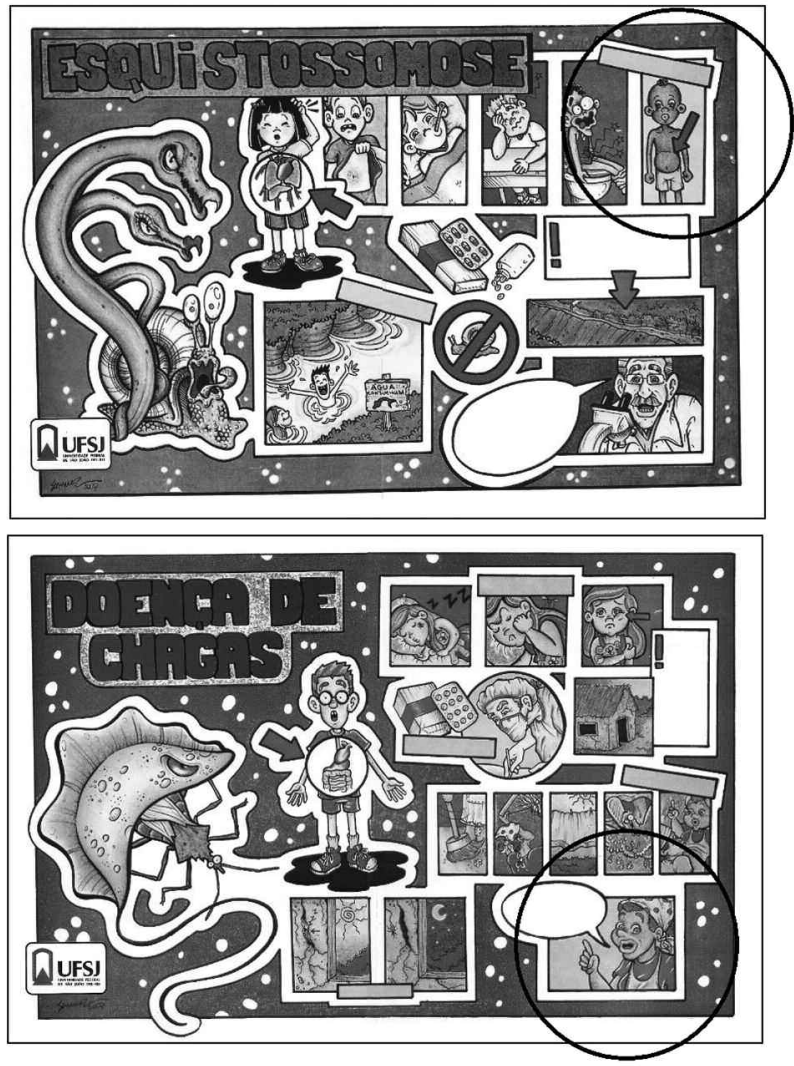
Estas análises relacionadas à etnia e gênero servem de subsídio para uma análise pós-colonialista destes materiais didáticos, a qual estaria atenta às formas aparentemente benignas de como o outro é representado. Para Silva (2010), uma análise pós-colonialista do currículo escolar buscaria identificar como as narrativas que o constituem atuam na construção de “concepções sobre 'raça', gênero e sexualidade" e que contribuem "para marginalizar identidades que não se conformam às definições da identidade considerada 'normal'" (Silva, 2010, p. 129). Por conseguinte, tendo em vista as figuras humanas inseridas nos cartazes, é possível perceber que nestas “formas superficialmente vistas como multiculturais, o Outro é 'visitado' de uma perspectiva que se poderia chamar de 'perspectiva do turista', a qual estimula uma abordagem superficial e vouyerística das culturas alheias" (Silva, 2010, p. 130). Desta forma, apesar de prematuro o desejo de fazer dos cartazes meios multiculturais, observa-se que a meta não foi atingida de forma eficaz, além de reforçar estereótipos indesejáveis.

\section{Considerações finais}

Após a análise realizada até aqui sobre estes materiais, reconhece-se que os cartazes produzidos tiveram aspectos favoráveis no período em que foram usados no programa de controle de parasitoses. A mediação dos professores no processo de construção de saberes sobre parasitoses com a utilização dos materiais produzidos, além de suas potencialidades de apoio às atividades curriculares, ainda carece ser pesquisada. Entretanto, as falhas de ordem ideológica - quando reforçam preconceitos de gênero e étnico - e de ordem conceitual levam à necessária inutilização dos materiais durante a continuidade do programa. Destacamos, ainda, que as análises e discussões aqui realizadas, em especial aquelas que se referem à identificação de estereótipos e preconceitos, devem contribuir para a disseminação de uma cultura de valorização da diversidade nas produções didáticas. Essa dinâmica de reconstrução da produção do material didático, a partir de uma reflexão teórica e metodológica sobre ele, é desejável e deve ser um processo contínuo.

Materiais de apoio a projetos de pesquisa e extensão universitária são comuns e muitas vezes considerados apenas em sua ideia essencial, nas suas intenções. Propomos com esse trabalho uma dinâmica de análise de materiais didáticos que extrapola sua utilização imediata, fazendo da pesquisa do material produzido um componente potencial da construção de conhecimentos do próprio grupo de pesquisa que os produziu. A reflexão sobre a produção levou a novas bases teóricas, que serão levadas em conta para a produção de outros tipos de materiais, e a divulgação desse processo pode 
potencializar essas reflexões por outros grupos e em diferentes áreas do conhecimento. Espera-se, assim, que novas abordagens e aperfeiçoamentos possam vir a ocorrer, tanto para os materiais que estamos produzindo, quanto para o campo da Educação em Saúde.

\section{Agradecimentos}

O projeto teve apoio da Fundação de Amparo à Pesquisa do Estado de Minas Gerais (Fapemig), na forma de financiamento e de bolsa de iniciação científica e do Programa de Extensão Universitária do Ministério da Educação.

\section{Notas}

1 Mestrando em Educação da Universidade Federal de São João Del-Rei (UFSJ), São João Del-Rei, Minas Gerais, Brasil.<samuel-qr@hotmail.com>

Correspondência: Av. Leite de Castro, 1.092, Fábricas, CEP 38301-180, São João Del-Rei, Minas Gerais, Brasil.

2 Mestrando em Epidemiologia em Saúde Pública da Escola Nacional de Saúde Pública Sergio Arouca, Fundação Oswaldo Cruz (Ensp/Fiocruz), Rio de Janeiro, Brasil. $<$ viniciusbelo4@hotmail.com>

3 Mestrando em Ciências da Saúde do Instituto de Pesquisas René Rachou, Fundação Oswaldo Cruz (CPqRR, Fiocruz), Belo Horizonte, Minas Gerais, Brasil. $<$ brunowarlley@hotmail.com>

4 Graduanda em Pedagogia da Universidade do Estado de Minas Gerais (UEMG), Barbacena, Minas Gerais, Brasil.<jacquelinebelo@gmail.com>

5 Professora adjunta do Departamento de Ciências Naturais da Universidade Federal de São João Del-Rei (UFSJ), São João Del-Rei, Minas Gerais, Brasil. Doutora em Biologia Funcional e Molecular pela Universidade Estadual de Campinas (Unicamp). <priscila@ufsj.edu.br>

6 Professor da Universidade Federal de São João Del-Rei (UFSJ) e diretor do Campus Centro-Oeste Dona Lindu (CCO-UFSJ), Divinópolis, Minas Gerais, Brasil. Doutor em Biologia Parasitária pela Fundação Oswaldo Cruz (Fiocruz). <silvaedu@ufsj.edu.br> 


\section{Referências}

BRUZZO, Cristina. Biologia: educação e imagens. Educação \& Sociedade, Campinas, v. 25, n. 89, 2004.

CANDEIAS, Nelly Martins Ferreira. Conceitos de educação e de promoção em saúde: mudanças individuais e mudanças organizacionais. Revista Saúde Pública, São Paulo, v. 31, n. 2, 1997.

CARUSO, Francisco; CARVALHO, Miriam de; SILVEIRA, Maria Cristina. Uma proposta de ensino e divulgação de ciências através dos quadrinhos. Ciência \& Sociedade, Rio de Janeiro, n. 8, 2002.

FACCION, Gabriela; FERNANDES, Priscila Correia. Diversity and biocultural preservation through an ethnobiological study in São João del-Rei, MG: an education proposal. In: INTERNATIONAL CONGRESS OF ETHNOBIOLOGY, 11., 2008, Cuzco. Anais..., 2008a.

Identificação da biodiversidade nativa por jovens em idade escolar no município de São João del-Rei, MG: um estudo etnobiológico. In: CONGRESSO DE PRODUÇÃO CIENTÍFICA DA UFSJ, 7., 2008, São João del-Rei, MG. Anais..., 2008b.

FOGAÇA, Adriana Galvão. A contribuição das histórias em quadrinhos na formação de leitores competentes. Revista PEC, Curitiba, v. 3, n. 1. 2002.

FREIRE, Paulo. Pedagogia da autonomia. 39. ed. São Paulo: Paz e Terra. 2009.

GOLDBERG, Luciane Germano; YUNES, Maria Angela Mattar; FREITAS, José Vicente de. O desenho infantil na ótica da ecologia do desenvolvimento humano. Psicologia em Estudo, Maringá, v. 10, n. 1, 2005.

MOHR, Adriana. Análise do conteúdo de 'saúde' em livros didáticos. Ciência \& Educação, Bauru, v. 6, n. 2, 2000.
MORATO, Marina Azevedo et al. Representação visual de estruturas biológicas em materiais de ensino. História, Ciências, Saúde-Manguinhos, Rio de Janeiro, v. 5, n. 2, 1998.

OLIVEIRA, Ricardo Lourenço de; CONDURU, Roberto. Nas frestas entre a ciência e a arte: uma série de ilustrações de barbeiros do Instituto Oswaldo Cruz. História, Ciências, Saúde-Manguinhos, Rio de Janeiro, v. 11, n. 2, 2004.

QUEIROZ, Gloria Regina P. C.; BARBOSALIMA, Maria da Conceição A. Conhecimento científico, seu ensino e aprendizagem: atualidade e construtivismo. Ciência \& Educação, Bauru, v. 13, n. 3. 2007.

ROSSI, Samuel Quinaud. Biologia ilustrada: um estudo sobre o uso de ilustrações no ensino de biologia e em um projeto voltado ao controle de parasitoses. Monografia. São João del-Rei: Faculdade de Ciências Biológicas, UFSJ, 2008.

SANTOS, Juliana Cristina dos et al. Análise comparativa do conteúdo Filo Mollusca em livro didático e apostilas do ensino de Cascavel, Paraná. Ciência \& Educação, Bauru, v. 13, n. 3, 2007

SCHALL Virginia Torres, STRUCHINER, Miriam. Educação em Saúde: novas perspectivas. Cadernos de Saúde Pública, Rio de Janeiro, v. 15, n. 2, 1999.

SILVA, Tomaz Tadeu. Documentos de identidade: uma introdução às teorias do currículo. 3 ed. Belo Horizonte: Autêntica. 2010.

SUCCI, Camila de Menezes; WICKBOLD, Daniela; SUCCI, Regina Célia de Menezes. A vacinação no conteúdo de livros escolares. Revista da Associação Médica Brasileira, São Paulo, v. 51, n. 2, 2005. 
TOSCANI, Nadima Vieira et al. Desenvolvimento e análise de jogo educativo para crianças visando à prevenção de doenças parasitológicas. Interface - Comunicação, Saúde, Educação, Botucatu, v. 11, n. 22, 2007.

Recebido em 02/02/2011

Aprovado em 29/08/2011 